\section{What Is Evolution?}

The Structure of Evolutionary Theory

By Stephen J. Gould (2002) The Belknap Press of Harvard University Press, Cambridge MA. 1433 pp + illustrations, tables, bibliography, index. \$39.95 (H). ISBN 0-674-00613-5.

Genetics, Paleontology, and

Macroevolution. 2nd ed.

By Jeffrey S. Levinton (2001) Cambridge University Press, Cambridge. 617 pp + illustrations, tables, glossary, bibliography, authior and subject indices. $\$ 150.00(\mathrm{H})$, $\$ 55.00$ (P). ISBN 0-521-80317-9.

\section{What Evolution Is}

By Ernst Mayr (2001) Basic Books, Perseus Books Group: New York. 318 $\mathrm{pp}+\mathrm{xv}$, illustrations, tables, appendices, glossary, bibliography, index. $\$ 26.00(\mathrm{H})$. ISBN 0-465-04425-5.

o what is evolution? For those in my generation, seeped in populational thinking and motivated by the excitement of the Evolutionary Synthesis ${ }^{1}$ at work revising the typological and often theory-free interpretations in paleoanthropology, evolution is Animal Species and Evolution, ${ }^{2}$ Ernst Mayr's fabulous, comprehensive rewrite of his much less accessible Systematics and the Origin of Species. ${ }^{3}$ It was easy to believe that there would never be anything else like it, but this did not turn out to be true. The full impact of Sewall Wright's writings was only felt over generations, as evolutionists were increasingly trained in population genetics and as Wright's views matured. Another key development was the appreciation of the importance of intellectual history, a topic subsequently explored by Mayr himself. ${ }^{4}$ The appreciation not always to avoid repeating the history; so heavy were casualties of the warring biopolicies of the last century that in some cases history requires repetition. Molecular data were always important in evolutionary thinking, but as molecular information was directly obtained, clarified and verified, and

Evolutionary Anthropology 12:53-55 (2003)

DOI 10.1002/evan.10100

Published online in Wiley InterScience

(www.interscience.wiley.com). available at higher resolution-finally as molecular genetics-it became a sometimes sister and sometimes alternative source of information. And phylogenetics emerged as the first clear approach to developing testable hypotheses of relationship. More than once, these new developments combined with each other and with Animal Species in strange and unexpected ways, and on occasion made for even stranger bedfellows. Our understanding of evolution is and may always be a work in progress and some, although not all of these developments, are reflected in the seminal volumes by Gould, Levinton, and Mayr that are reviewed here.

The processes of speciation and their consequences are a significant aspect of all three works, and provide a framework for comparing and contrasting them. The importance of speciation in the evolutionary process is Stephen Jay Gould's signature argument. The punctuated equilibrium model he proposed with Niles Eldredge, ${ }^{5}$ provides a singular cause for evolutionary change as a consequence of the speciation process. This could fit well with phylogenetic approaches in which species are entities with definable beginnings and ends ${ }^{6}$ with their own unique evolutionary pathways, yet Gould was not a cladist. It is not clear why this was the case (neither "phylogenetics" nor "cladistics" appears in his index), but one possibility may be the difficulties in identifying homoplasies created by Gould's approach to adaptation. Punctuated equilibrium provides little room for the evolution of adaptations within species-hence the Spandrels argument ${ }^{7}$ - and the fact that there is an unpredictable element thrown into the details and specifics of adaptations which for the most part Gould believes were dictated by variations already present in a species for other reasons-a process he named "exaptation." ${ }^{8}$ Moreover, randomness plays a substantial role in Gould's approach to understanding the overall pattern of evolution, both because of the importance of the drift process that is often part of allopatric speciation, but more significantly because of the role extinctions play in his model, especially catastrophic, unpredictable extinctions. ${ }^{9}$ There are many origins for punctuated equilibrium (though only Gould and Eldredge put them all together); Mayr $^{2,10,21}$ more than any other laid out the argument for the importance of speciation and its significance in promoting evolutionary changes, and Douglas Futuyma ${ }^{11}$ addressed the importance of speciation in protecting evolutionary changes by isolating changes in protected gene pools.

Mayr only mentions punctuated equilibrium twice, and then briefly. One time is as an example of his speciational evolution ${ }^{12}$ wherein drift allows a "more or less profound genetic restructuring" as part of the speciation process, and the other in the appendix on criticisms of evolutionary theory, where he argued that the occurrence of punctuated equilibria is not in conflict with Darwinian gradualism, but as "strictly populational phenomena" this pattern is by definition gradual and "in no respect whatsoever in conflict with the conclusions of the evolutionary synthesis." 13

Jeffrey Levinton's discussion of punctuated equilibrium is elaborate and exhaustive. Like Mayr, albeit in much more detail, he argues that punctuated equilibrium is not an alternative to the more traditional models of evolutionary change, but is actually one of them. He is one of the most vocal critics of punctuated equilibrium, although for the most part this is because of his examination of the claims for stasis in the fossil record (which he describes as "straw men"), and his analysis of their theoretical underpinnings. He is critical of Futuyma's argument that speciation is required to protect genetic changes. Moreover, Futuyma's model does not take into account isolation by distance and the role it can play to establish and maintain significant geographic variation in the absence of selection when there is gene flow. ${ }^{14,15}$ When selection plays a significant role, long-standing clines created by selection and gene flow may characterize a stable pattern of variation across the geographic range of a spe- 
cies, and with population structure it is possible for genetic variation to be systematic and long lasting, without the expectation that such variation will necessarily be lost because of gene flow and reticulation. ${ }^{16}$

Gould's case for equilibrium between speciations came firstly from the fossil record, which he consistently interpreted to show long periods without change. The mechanism he proposed to account for this was the inflexible frame of developmental constraints that evolved in each species. In an approach similar to Wright's adaptive peaks, at least in an informal way, Gould argued that a tight system of developmental constraints meant that advantageous change in one element almost certainly would create unexpected and for the most part harmful consequences in others, and that this acted to brake gradual changes unless and until the linked developmental constraints could be deconstructed, as would be expected during the "genetic revolution" of peripatric speciation. ${ }^{10,12,17}$

One of Gould's most productive approaches in examining developmental constraints was to expand on ideas that were rampant in the evolutionary literature of the $19^{\text {th }}$ and earlier $20^{\text {th }}$ century. ${ }^{18}$ For example, early in his career, Gould grappled with the allometric constraint ${ }^{19}$ and, of course, develops this in The Structure $^{20}$ ("allometry" does not even appear in Mayr's ${ }^{21}$ index, he briefly dealt with it in Animal Species ${ }^{2}$ ). For Gould, allometry is a consequence of ontogenetic channeling and denotes a functional relationship between allometrically scaled features. But Russell Lande $^{22}$ (not in Gould's bibliography) showed that allometry could be explained through qualitative genetics, describing a relationship between variables that results from genetic correlation between features, in a model similar to Gillespie's idea of draft. ${ }^{23}$ For Lande, the allometric relation-meaning the effect that selection on one character has on another-can be predicted from the characteristics of the covariance matrix. Selection on one feature may create correlated change in another, with constraints Lande describes as allometric, but there is no reason to suppose that the allometric changes associated with adaptive changes in one feature are necessarily adaptive in another. Levinton developed the developmental constraint aspect of allometry even further, and rejects it as an explanation of correlated change. He described Lande's genetic correlation explanation for allometry as pleiotropy and dismisses it as well, on the argument that genetic correlations cannot be overcome. But this is almost certainly not the case, as disrupting genetic correlations is what the genetic revolutions of speciation is all about, and in any event Lande ${ }^{22}$ did not argue the genetic correlations needed to be disrupted to explain allometry. Quite to the contrary, his contention was that genetic correlations constrained the direction of correlated genetic change, but at the same time genetic correlations continually change under the action of selection on one or both of the correlated traits.

And now, in The Structure, Gould admits that the two key ideas of punctuated equilibrium were wrong. "Eldredge and I made a major error by advocating, in the original formulation of our theory, a direct acceleration of evolutionary rate by the process of speciation;" and further, now admits that developmental constraints do not provide internal resistance to selection. Levinton discusses many of the cases Gould used to show the fossil record revealed long periods of stasis, and for the most part found the evidence wanting. In many of these cases the evidence against gradualism is not evidence of no change, but evidence that adaptive change and species transformations did not persist in a constant manner. It is this cartoon-like characterization of gradualism that Levinton calls the "straw man." Moreover as it turns out, many other examples once used to support the claim of stasis in the fossil record were incorrectly interpreted, according to Levinton. One example near and dear to my heart ${ }^{24}$ is in the debate over claims of stasis in Homo erectus evolution,5,25 claims which Levinton also disputes, and now even Gould describes himself 26 as casting "a tentative vote by this juror, despite his general biases in the other direction, for at least some fairly persuasive gradu- alism within this species." Gould, of course, has not abandoned punctuated equilibrium, so one might ask what he believes accounts for the pattern. In a phrase, it is species selection, ${ }^{27}$ what Gould has come to call "hierarchical selection"28_the idea that selection can validly apply both above the populational level as species taxa have differential reproduction (speciations) and survivorship (extinctions), and also apply at the genic level below. ${ }^{29}$

For those of us who study the past these are exciting books, both for understanding key parts of evolution as it is conceived today, and the halfcentury of developing evolutionary theory this reflects. How has this development affected paleoanthropology? The simple answer is often not very much. The "Presapiens Theory" has returned, ${ }^{30}$ with a new essentialism $^{31}$ that brings a taxonomizing of normal geographic and temporal variation to undreamed of heights. Several essays on the last fifty years of paleoanthropology in this journal ${ }^{32,33}$ have implied that the Evolutionary Synthesis, especially as reflected in Mayr's work, has set paleoanthropology back, misleading paleoanthropologists and creating prejudices only now being overcome. I do not see it this way, and fear that the problems in our profession come far more from misunderstanding and disregarding the Evolutionary Synthesis and the ways evolutionary theory has developed since, than from the consequences of accepting it and its emphasis on populational thinking. In parts of our profession, the Evolutionary Synthesis is equated with linear progressionism; for instance, "thanks to the overwhelming triumph of the Evolutionary Synthesis . . human evolution, like that of other organisms, came to be seen as a gradual, linear process that, come hell or high water, continued doggedly along a path of inexorable betterment." 34 Population genetics is not fully integrated into paleoanthropological thinking, so that evolutionary mechanisms are accepted that do not include the consequences of independent assortment and crossover; “' 'adaptations' cannot be independent entities whose histories can be followed independently of 
those of the taxa within which they are embedded... natural selection can ... only vote up or down on the success of the whole individual, not on that of its separate components." 35 Evolutionary models continue to be proposed that ignore aspects of gene flow and population structure that have been part of population genetics modeling for decades; "evolutionary change may or may not produce speciation, but at the micro-level it will be a process of cladogenesis, not anagenesis." 36 Phylogenetics can also be a problem area; clades ${ }^{37}$ are described without a single synapomorphy linking the species hypothesized to be in them. ${ }^{38}$ These problems exist within a fringe of paleoanthropology, not at its central thrust into the future that is largely a consequence of the anthropologists in the profession, but it is a vocal and powerful fringe that, if successful, could deflect this thrust and prevent the final integration of paleoanthropology into normal biological science.

\section{REFERENCES}

1 Alternatively called the Modern Synthesis or the New Synthesis.

2 Mayr E. 1963. Animal species and evolution. Cambridge: Belknap Press of Harvard University Press.

3 Mayr E. 1942. Systematics and the origin of species. New York: Columbia University Press.

4 Mayr E. 1982. The Growth of biological thought: diversity, evolution, and inheritance. Cambridge: Belknap Press of Harvard University Press.

5 Gould SJ, Eldredge N. 1977. Punctuated equi- libria: the tempo and mode of evolution reconsidered. Paleobiology 3:115-151.

6 Wiley EO. 1981. Phylogenetics. The theory and practice of phylogenetic systematics. New York: John Wiley \& Sons.

7 Gould SJ, Lewontin RC. 1979. The spandrels of San Marco and the Panglossian paradigm: a critique of the adaptationalist programme. Proc Roy Soc, London, ser B, 205:581-598.

8 Gould SJ, Vrba E. 1982. Exaptation-a missing term in the science of form. Paleobiology 8:4-15. 9 Gould SJ. 1989. Wounderful life: The Burgess Shale and the nature of history. New York: Norton.

10 Mayr E. 1988. Does microevolution explain macroevolution? In: Mayr E, editor. Toward a new philosophy of biology. Cambridge: Harvard University Press. p 402-422.

11 Futuyma DJ. 1987. On the role of species in anagenesis. Am Nat 130:465-473.

12 Mayr E. 1954. Change of genetic environment and evolution. In: Huxley JS, Hardy AC, Ford EB, editors. Evolution as a process, London: Allen and Unwin. p 157-180.

13 Ref, 21, p. 270.

14 Wright S. 1943. Isolation by distance. Genetics 28:114-138.

15 Eller E. 1999. Population substructure and isolation by distance in three continental regions. Am J Phys Anthrop 108:147-159.

16 Wolpoff MH, Caspari R. 1997. Race and human evolution. New York: Simon and Schuster. 17 Carson HL, Templeton AR. 1984. Genetic revolutions in relation to species phenomena: the founding of new populations. Ann Rev Ecol and Syst 15:97-131.

18 Alberch P, Gould SJ, Oster GF, Wake DB. 1979. Size and shape in ontogeny and phylogeny. Paleobiology 5:296-317.

19 Gould SJ. 1966. Allometry and size in ontogeny and phylogeny. Biol Rev 41:587-640.

20 Gould SJ. 2002. The structure of evolutionary theory. Cambridge: Harvard University Press.

21 Mayr E. 2001. What evolution is. New York: Basic Books.

22 Lande R. 1979. Quantitative genetic analysis of multivariate evolution, applied to brain: body size allometry. Evolution 33:402-416.

23 Gillespie JH. 2001. Is the population size of a species relevant to its evolution? Evolution 55: 2161-2169.
24 Wolpoff MH. 1984. Evolution in Homo erectus: the question of stasis. Paleobiology 10:389406.

25 Rightmire GP. 1981. Patterns in the evolution of Homo erectus. Paleobiology 7:241-246.

26 Ref. 20, p. 833.

27 Vrba ES. 1980. Evolution, species, and fossils: how does life evolve? S Afr J Sci 76:61-84.

28 Gould SJ. 1982. The meaning of punctuated equilibrium and its role in validating a hierarchical approach to macroevolution. In: Milkman R, editor. Perspectives on Evolution. Sunderland: Sinauer Associates. p 83-104.

29 Although he has always been hostile to this logical extension of hierarchical selection, denying validity to genic level selection, especially in considerations of inclusive fitness.

30 Hawks J, Wolpoff MH. 2003. Sixty years of modern human origins in the American Anthropological Association. Am Anthropol (in press).

31 Caspari R. 2003. From types to populations: a century of race, physical anthropology, and the American Anthropological Association. Am Anthropol (in press).

32 Foley R. 2001. In the shadow of the modern synthesis? Alternative perspectives on the last fifty years of paleoanthropology. Evol Anthropol 10:5-14.

33 Tattersall I. 2000. Paleoanthropology: The last half-century. Evol Anthropol 9:2-16.

34 Tattersall I. 2002. The Monkey in the eirror. Essays on the science of what makes us human. New York: Oxford. p 81.

35 Ref. 33, p. 8.

36 Ref. 32, p. 10.

37 Levinton defines monophyletic group as "a group of species that includes a species [or hypothesized ancestral species defined by a set of character states] and all of its descendants."

38 Wood BA. 2002. Palaeoanthropology: hominid revelations from Chad. Nature 418:133-135.

Milford H. Wolpoff Paleoanthropology Laboratory Department of Anthropology University of Michigan Ann Arbor, Ml 48109-1382 e-mail: wolpoff@umich.edu (c) 2003 Wiley-Liss, Inc. 